\title{
Estimating the effect of equipment reliability indices, schedules, and regular overhaul scopes on reliability and efficiency of combined heat and power plants
}

\author{
Elena Stepanova ${ }^{1, *}$, Alexey Maksimov ${ }^{1}$ \\ ${ }^{1}$ Melentiev Energy Systems Institute of Siberian Branch of Russian Academy of Sciences, Russia
}

\begin{abstract}
We have developed a technique and a programming-computing suite (PCS) to estimate the effect of equipment reliability indices, schedules, and regular overhaul scopes on reliability and efficiency of combined heat and power plants (CHPPs). We describe the approach to predict heat and electric loads for the investigated CHPP operation period, taking into account the features of the power cogeneration. We performed optimization studies of two operation periods (different in overhaul resources) for an industrialheating CHPP.
\end{abstract}

\section{Introduction}

The combined heat-and-power plants (CHPPs) maintained in the Russian Federation (RF) are often the only heat sources for their users. Currently, observed is a high percent of their equipment wear, which increases hazard of emergencies, reduces the energy and economic efficiency of their operation [1, 2]. Regular overhaul increases the duration and reliability of equipment operation at power plants. Besides, one should take into account the cogeneration sector transition to market relations in many RF regions, where CHPPs are difficult to compete with hydro- and condensation power plants (CPPs) in benefitting, when participating at the Wholesale Electricity Market (WEM) [3-5].

\section{Problem statement}

Reducing overhaul intervals and increasing overhaul operation scopes enable to decrease the number of equipment emergency failures and undersupply of heat and electricity for users, but increases the down time and equipment regular overhaul expenditures that are an essential part of operating costs. Reducing regular overhaul scopes and increasing the overhaul intervals reduces the equipment down time, but increases the number of possible failures that, considering climate features of many RF regions, may lead to serious consequences. Therefore, to solve this problem, it is relevant to determine optimal overhaul interval durations and regular overhaul scopes for CHPP turbo- and boiler units, at which all requirements for the power supply reliability and operation features of each power installation are met. Performing such studies may be implemented through mathematical simulation and optimization [6-9].
Solving this problem required developing a technique to estimate the effect of equipment reliability indices, schedules, and overhaul scopes on the CHPP operation, and a programming and computing suite (PCS) implementing that technique. Figure 1 presents the PCS structure comprising four main blocks.

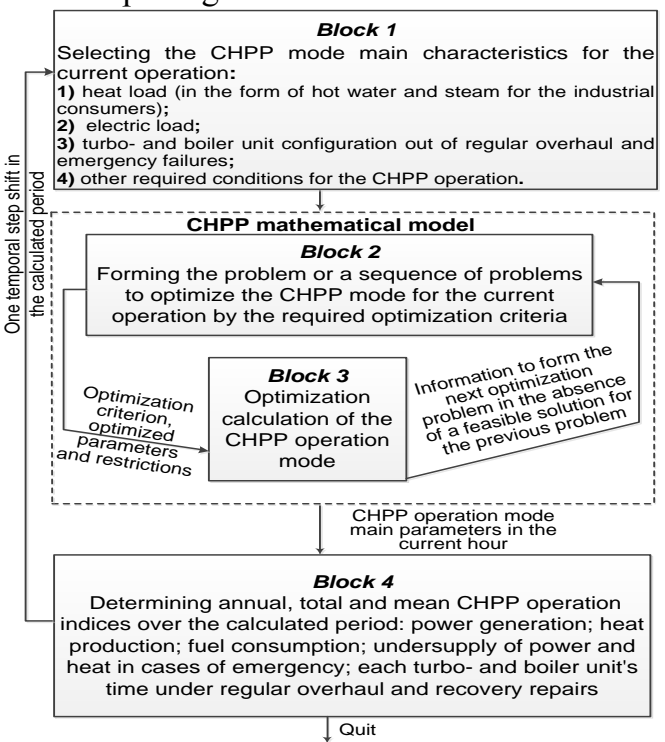

Figure 1. PCS structure to estimate the effect of the equipment reliability indices, schedules, and overhaul scopes on CHPP operation reliability and efficiency.

In our study, we accepted the following general provisions. Each turbo- and boiler unit may be in the following conditions: operation, redundancy, regular overhaul, and emergency repair. Regular overhauls are held in certain number of operation hours with certain equipment idle hours. Simultaneous different regular overhauls [10] are admitted. The turbo- or boiler unit emergency shutdown, with a subsequent regenerative 
repair, is addressed as a random event. After an emergency failure, a post-damage repair follows for a given renewal time. To simulate emergency failures, we use random-number generators. To more precisely estimate the selection of the overhaul schedule, it is desirable to address the CHPP operation period in 10 and more years. Over the addressed time interval, the CHPP operation mode main conditions are formed depending on necessity of detailing the problem solution for each hour, three, six, or twelve hours.

\section{Block 1}

PCS Block 1 forms the CHPP mode main characteristics for the operation at the current instant. Figure 2 presents the PCS Block 1 structure.

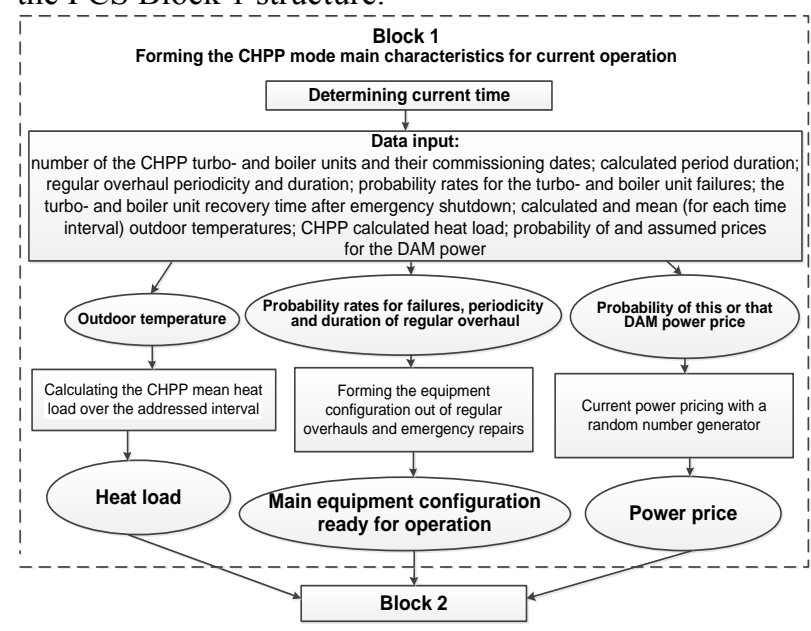

Figure 2. Structure of the PCS Block 1 to estimate the effect of equipment reliability indices, schedules, and overhaul scopes on CHPP reliability and efficiency.

The set parameters for Block 1 are: the number of CHPP turbo- and boiler units, and their commissioning years; calculated period duration; periodicity and durations of regular overhauls; turbo- and boiler units' failure probabilities determined by the parameters of failure flows and recovery time for turbo- and boiler units after an emergency shut-down (statistical data); calculated and mean air temperature for each time interval, the CHPP calculated heat load; the day-aheadmarket (DAM) power estimated prices and probabilities of their appearance. The computed parameters are: the CHPP heat load (in the form of hot water), the price of the electric power and the composition of the capital equipment that is not under regular overhaul and emergency failures within the current calculated interval.

Due to the features of the CHPP combined power generation, we use the following approach to determine the heat and power loads at a power plant. Because the heat load of the hot-water supply (HWS) and of the CHPP heating depends directly on the air temperature, we address a year monthly, a month is split into three time intervals with the mean air temperature characteristic of each interval. The mean air temperature is obtained from meteorological data for the certain region in the last 10 years and more. Further, based on the air temperature, user's calculated load, and the HWS share, we determine the HWS and the heating mean loads for the calculated time interval [11]. The heat energy supply in the form of steam for industrial consumers is accepted equal to the contract heat load in steam.

To determine the CHPP electric load, we use the approach explicitly described in [12, 13]. Its essence is as follows. For the WEM participants, the power scopes not covered by regulated contracts are sold at nonregulated prices within free contracts, at the DAM, and the balancing market. I.e., there is an electricity price uncertainty that causes an uncertainty of the CHPP electric power. The CHPP operation within electric load maxima is sufficiently difficult due to a poor maneuvering of major steam-electric generating units, especially for the plants with an inadequate number of peak hot-water boilers. At the same time, the electric power generated at a CHPP in the condensation mode is expensive; therefore, it is profitable to sell it within its price maxima periods.

In our study, we address a version of CHPP possible participation at the DAM. The CHPP electric output at the DAM $\left(N^{C H P P}\right)$ depends on the DAM price

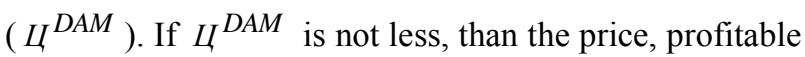
for CHPP in the condensation mode ( $L_{\text {COn }}^{C H P}$ ), the CHPP will bear the greatest possible electric load. If

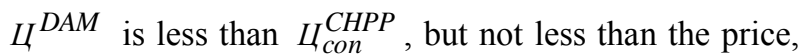
at which the CHPP operating in the heat-extraction mode $\left(L_{\max h}^{C H P P}\right)$ agrees to sell its electric power, the plant will bear the greatest electric load (possible for the heatextraction mode) equal to $N_{\max h}^{C H P P}$. Otherwise, the CHPP load will be minimally possible ( $N_{\min h}^{C H P P}$ ). The specified assignment rules ${ }_{N}$ CHPP are determined through the following system of logical conditions.

$$
N^{C H P P}=\left\{\begin{array}{l}
N_{c O n}^{C H P P}, L_{c o n}^{C H P P} \leq L^{D A M} \\
N_{\max h}^{C H P P}, L_{c o n}^{C H P P}>L^{D A M} \geq L_{\max h}^{C H P P} \\
N_{\min h}^{C H P P}, L_{\max h}^{C H P P}>\bigsqcup^{D A M}
\end{array}\right.
$$

Based on the statistical data analysis or predicted studies of supply point groups (SPGs), to which the addressed CHPP relates to, one may determine the probability of

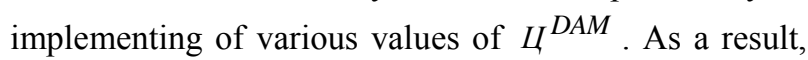
we obtain probabilities $P_{1}, P_{2} \ldots P_{n}$, corresponding to various DAM values $\bigsqcup_{1}^{D A M}, L_{2}^{D A M} \ldots, L_{n}^{D A M}$, where $n$ is the greatest possible DAM price. Herewith, the conditions $0 \leq P_{i} \leq 1, i=1 \ldots n, \sum_{i=1}^{n} P_{i}=1$ should be met.

\section{Blocks 2 and 3}

Like one can see from Figure 1, after the formation of the CHPP main operation conditions, there occurs a transition to optimization problems. Optimization 
calculations are performed through a CHPP mathematical model created by the Computerized Programming System (CPS PCS) developed earlier at the Melentiev Energy Systems Institute of the Siberian Branch of the Russian Academy of Sciences [7, 14]. The CHPP model comprises mathematical models for CHPP individual equipment elements. The models describe in detail the processes occurring in the equipment, and are based on physical laws and existing methods of calculating heat-and-power installations (HPIs) (energy and material balances of energy carriers, processes of expansion and compression of working substances, standard method for thermal calculation of a boiler unit, etc.).

The first problem to solve is the maximizing profit problem, when optimizing the main operating configuration created in Block 1 (the configuration out of regular overhauls and emergency failures). The technique of optimizing the equipment configuration is described in detail in $[15,16]$. In the CHPP mathematical model under creation, we introduce auxiliary, material variables, whose variation from 0 to 1 (for one boiler or turbounit) enables to estimate the necessity to include/exclude this or that generating equipment in/out the CHPP operation.

Mathematical statement of the problem to gain additional profit from selling electric power at the DAM (when optimizing the equipment configuration) has the following view

$$
\max _{x, d, N^{C H P P}} \operatorname{Pr},
$$

under the conditions

$$
\begin{gathered}
y=H\left(x, Q, N^{C H P P}\right), G\left(x, y, Q, N^{C H P P}\right) \geq 0,(3) \\
{ }_{B}^{C H P P}=\varphi\left(x, y, Q, N^{C H P P}\right), \\
N_{\min h}^{C H P P} \leq N^{C H P P} \leq N_{c o n}^{C H P P}, x \leq x \leq \bar{x}, \\
0 \leq d \leq d^{\max },
\end{gathered}
$$

where $y$ is the vector of dependent optimized parameters (direct steam discharge for turbines, steam discharges from non-controllable turbine withdrawals, electric powers of turbines, pressure in non-controllable turbine withdrawals, etc.); $x$ is the vector of independent optimized parameters (steam discharges in turbine condensers and steam discharges from regulated turbine withdrawals, pressure ahead of turbine regulating diaphragms, etc.); $H$ is the $p$-dimensional vector-function of restrictions-equalities; it includes the equations describing technological links among the scheme elements, energy and material balances of the CHPP technological scheme elements, etc.; $Q$ is the vector of the power plant's heat load values; $B^{C H P P}$ is the CHPP boiler-unit total fuel consumption; $\underline{x}$ and $\bar{x}$ are the vectors setting the intervals for the variation in the optimized parameters of the installation; $d$ is the determined operating equipment configuration.

If the first problem has a feasible solution, then the second problem of the profit maximization is solved at already fixed equipment configuration obtained as a result of solving the first problem. Fixation occurs as follows. The equipment configuration obtained by rounding the auxiliary variables to the proximal entire quantities may be considered optimal, if, as a result of solving the first problem, the $\left|d_{i}-d_{N_{i}}\right| \leq \varepsilon$ condition is met for the obtained values of the operating aggregate auxiliary variables. Here, $d_{N_{i}}$ is an entire quantity meeting the $0 \leq d_{N_{i}} \leq d^{\max }$ condition, $d^{\max }$ is the maximal given configuration of the operating equipment. In the optimization calculations through the given methodical approach, the value $\varepsilon$ was accepted equal to 0,15 [16]. At the numerical value of the auxiliary variable (upon rounding) of this or that aggregate equal to 0 , there occur logical conditions for its exclusion from calculating the CHPP operation mode. The mathematical statement of the second problem will correspond to (15 ), but instead of Condition (6), the next condition is considered:

$$
d^{t} \in D,
$$

where $d^{t}$ is the fixed value for the vector of discrete variables $d ; D$ is the assemblage of optimally "suspicious" versions of the equipment configuration (it is formed taking into account the equipment in the operable state).

As a result of solving the second problem, we determine the CHPP operation mode that provides the consumers' needs in heat and power and gains the greatest possible profit at such a mode from selling power. In case of the DAM low price, we obtain the mode with the complete power supply to the consumers, but without CHPP participation at the DAM.

In cases of emergency failures of this or that equipment, or when a regular overhaul coincides with an emergency failure, solving the first problem may show that the CHPP, in such situations, is not able to provide the consumers with necessary supplies (heat load in the form of hot water and steam, and electric power generated by heat consumption). Then, we switch to solving a sequence of problems to minimize the energy undersupply to consumers. It is necessary to clarify in advance, what loads of the CHPP external consumers are subject to reducing, first of all. The CHPP electric and heat loads are ranked by "importance" degrees. Further, one solves (in the ascending order of "importance") a sequence of problems to minimize undersupplies of electric and heat loads of a power plant. In greater detail, these problems are described in [17]

Upon calculating the CHPP operation mode at a current instant, the following main indices are passed from Block 3 into Block 4: CHPP electric and heat loads, electric output for the CHPP internal needs, operating equipment configuration, fuel consumption, undersupplies of electric and heat energy, operation, reserve, regular overhaul, and recovery repair durations for each turbo and boiler unit. Next, by the PCS time meter, there occurs a time shift (1 hr, 3- or 6-hr, etc.), and the calculations continue until the entire calculated period is studied. 


\section{Blocks 4}

In Block 4, the CHPP operation indices - annual, total, and mean over the entire calculated period - are calculated: power generation, heat production, fuel consumption, power and heat undersupplies in emergency cases, operation, reserve, regular overhaul, and recovery repair durations for each turbo and boiler unit.

$$
\begin{array}{r}
\Im_{\text {ann }}^{C H P P}=\sum_{i=1}^{n} N_{i}^{C H P P} T_{i}, \ni_{c . p .}^{C H P P}=\sum_{k=1}^{K} \ni_{k}^{C H P P}, \\
Q_{a n n}^{C H P P}=\sum_{i=1}^{n} Q_{i}^{C H P P} T_{i}, Q_{c . p .}^{C H P P}=\sum_{k=1}^{K} Q_{k}^{C H P P}, \\
B_{\text {ann }}^{C H P P}=\sum_{i=1}^{n} B_{i}^{C H P P} T_{i}, B_{c . p .}^{C H P P}=\sum_{k=1}^{K} B_{k}^{C H P P}, \\
\Delta \Im_{\text {ann }}^{C H P P}=\sum_{i=1}^{n}\left(N_{i}^{r}-N_{i}^{a c}\right) T_{i}, \Delta \Im_{c . p .}^{C H P P}=\sum_{k=1}^{K} \Delta \ni_{k}^{C H P P}, \\
\Delta Q_{a n n}^{C H P P}=\sum_{i-1}^{n}\left(Q_{i}^{r}-Q_{i}^{a c}\right) T_{i}, \Delta Q_{c . p .}^{C H P P}=\sum_{k=1}^{K} \Delta Q_{k}^{C H P P},
\end{array}
$$

where, $\ni_{\text {ann }}^{C H P P}$ is the CHPP annual power generation; ${ }_{{ }_{\text {c.p. }}^{C H P P}}$ is the CHPP power generation for the calculated period $K$ comprising $k$ years; $N_{i}^{C H P P}$ is the CHPP power output in the $i$-mode; $T_{i}$ is the time interval $(1 \mathrm{hr}$ in this paper); $Q_{a n n}^{C H P P}$ is the CHPP annual heat production; $Q_{c . p .}^{C H P P}$ is the CHPP heat production over the calculated period $K ; Q_{i}^{C H P P}$ is the CHPP heat production in the $i$-mode; $B_{a n n}^{C H P P}$ is the CHPP annual fuel consumption; $B_{c . p .}^{C H P P}$ is the CHPP fuel consumption over the calculated period $K ; B_{i}^{C H P P}$ is the CHPP fuel consumption in the $i$-mode; $\triangle Э_{a n n}^{C H P P}$ is the annual power undersupply to consumers; $\triangle \Im_{c . p .}^{C H P P}$ is the power undersupply to consumers over the calculated period $K ; N_{i}^{r}$ is the required minimally-possible power output generated at the heat consumption by the CHPP operating turbounits in the $i$-mode; $N_{i}^{a c}$ is the actual maximally-possible power output in the $i$-mode; $\triangle Q_{a n n}^{C H P P}$ is the annual heat undersupply to consumers; $\triangle Q_{c . p .}^{C H P P}$ is the heat undersupply to consumers over the calculated period $K ; Q_{i}^{r}$ is the required heat supply to consumers in the $i$-mode; $Q_{i}^{a c}$ is the actual heat supply to consumers in the $i$-mode; $n$ is the total number of modes per year.

To estimate the effect of various schedule versions, of the regular overhaul scopes, and of the equipment reliability indices on the CHPP operation efficiency in general, one may use the obtained mean-annual values for the entire calculated period, because all the annual indices depend on random values (possible emergency failures and probabilities of this or that DAM price).

$$
\begin{gathered}
\bar{Э}_{c . p .}^{C H P P}={ }^{C H . p .} /_{K}^{C H P P}, \bar{Q}_{c . p .}^{C H P P}=Q_{c . p .}^{C H P P} / K, \\
\bar{B}_{c . p .}^{C H P P}={ }_{C . p .}^{C H P P} / K, \\
\overline{\Delta Э}_{c . p .}^{C H P P}={ }^{\Delta Э_{c . p .}^{C H P P}} /{ }_{K}, \overline{\Delta Q}_{c . p .}^{C H P P}={ }^{\Delta Q_{c . p .}^{C H P}} / K
\end{gathered}
$$

where $\bar{Э}_{c . p .}^{C H P P}$ is the arithmetic mean value for the CHPP power generation over the calculated period $K$ comprising $k$ years; $\bar{Q}_{c . p \text {. }}^{C H P P}$ is the arithmetic mean value for the CHPP heat production over the calculated period $K ; \bar{B}_{\text {c.p. }}^{C H P P}$ is the arithmetic mean value for the CHPP fuel consumption over the calculated period $K ; \overline{\Delta Э}_{c . p}^{C H P P}$. is the arithmetic mean value for the power undersupply to consumers over the calculated period $K ; \overline{\Delta Q}_{\text {c.p. }}^{C H P P}$ is the arithmetic mean value for the heat undersupply to consumers over the calculated period $K$.

We suggest using the set energy supply assurance coefficient for each kind of energy produced by the CHPP as the CHPP complex reliability indices: $k_{\mathrm{c}}=1-\Delta \ni / \ni$, where $\Delta \ni, Э$ are the actual undersupply and the set supply of the energy for a certain period, respectively.

\section{Example}

The technique to estimate the effect of the CHPP reliability parameters, schedules, and regular overhaul scopes on the reliability and efficiency of its operation was tested by an example of an industrial-heating CHPP. Figure 3 shows its simplified flowsheet.

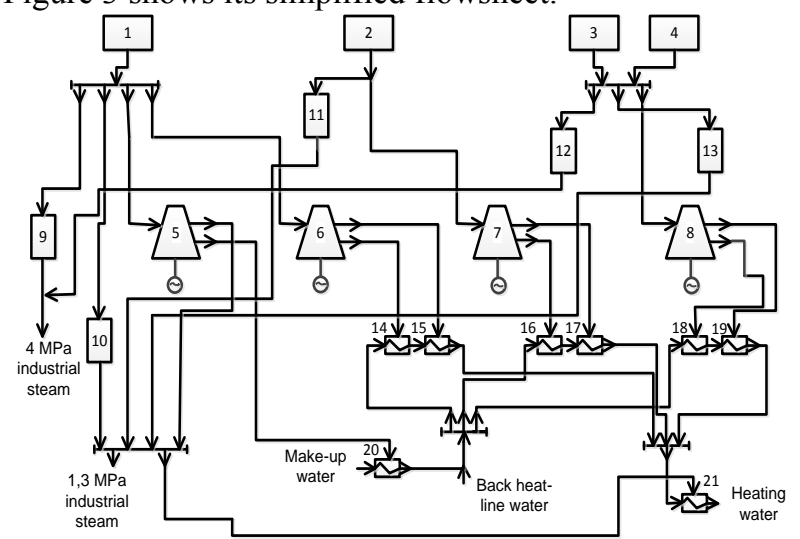

Figure 3. CHPP simplified flowsheet. Designations: 1 - a group of BKZ-420-140 steam boilers (4 pcs); 2 - a group of BKZ-500-140 steam boilers (2 pcs); 3 - a BKZ-500-140 steam boiler; 4 - a BKZ-820-140 steam boiler; 5 - a group of PT-60$130 / 13$ steam turbines (2 pcs); 6, 7 - T-175/210-130 steam turbines; 8 - a T-185/220-130 steam turbine; 9-13 - pressurereducing desuperheating stations; 14-19 - own network water heaterline heaters for the T-175/210-130 and T-185/220-130 turbines, respectively; 20 - a group of make-up water heaters; 21 - a group of plant main network water heaters.

In our study, we addressed two versions of the CHPP operation period. The versions differed in the overhaul period. Table 1 provides the input data. Table 2 presents 
the power prospective DAM prices and their appearance probabilities. These data were obtained based on statistical sampling for the characteristic period [12]. The price of the fuel used was $1400 \mathrm{rbl} . / \mathrm{t}$. s.f.

Table 1. Calculation input data.

\begin{tabular}{|c|c|c|}
\hline Parameters & Version 1 & Version 2 \\
\hline Calculated period/step, yrs/hrs & $15 / 6$ & $15 / 6$ \\
\hline $\begin{array}{c}\text { CHPP installed electric power, } \\
\text { MW }\end{array}$ & 655 & 655 \\
\hline Calculated heat load, Gcal/hr & 1147 & 1147 \\
\hline $\begin{array}{c}\text { Probability of the boiler unit } \\
\text { emergency failure, net }\end{array}$ & 0,0289 & 0,0289 \\
\hline $\begin{array}{c}\text { Boiler unit recovery time after } \\
\text { emergency failure, hrs }\end{array}$ & 38 & 38 \\
\hline $\begin{array}{c}\text { Probability of the turbounit } \\
\text { emergency failure, net }\end{array}$ & 0,0197 & 0,0197 \\
\hline $\begin{array}{c}\text { Turbounit recovery time after } \\
\text { emergency failure, hrs }\end{array}$ & 68 & 68 \\
\hline $\begin{array}{c}\text { General overhaul: } \\
\text { - overhaul period, hrs } \\
\text { - overhaul duration, CDs }\end{array}$ & 33000 & 46 \\
\hline $\begin{array}{c}\text { Mean overhaul: } \\
\text { - overhaul period, hrs }\end{array}$ & 9000 & 24 \\
\hline overhaul duration, CDs & 9500 & 24 \\
\hline $\begin{array}{c}\text { 1st class current overhaul: } \\
\text { - overhaul period, hrs }\end{array}$ & 2900 & 10 \\
- overhaul duration, CDs & 2920 & 10 \\
\hline 2nd class current overhaul: & & \\
- overhaul period, hrs \\
- overhaul duration, CDs
\end{tabular}

Table 2. Prospective electric power DAM prices and their appearance probabilities.

\begin{tabular}{|c|c|c|c|c|c|c|c|c|c|c|}
\hline Items & \multicolumn{10}{|c|}{ Values } \\
\hline $\begin{array}{c}\text { Price, } \\
\text { rbl./M } \\
\text { W hr }\end{array}$ & 0 & 8 & ঠి & ষ্ల & ஓ̊ & ¿ & రి & $\stackrel{8}{8}$ & రి & ஓ \\
\hline $\begin{array}{l}\text { Proba- } \\
\text { bility }\end{array}$ & $\begin{array}{l}0 \\
8 \\
0 \\
0\end{array}$ & $\begin{array}{l}\overline{0} \\
0\end{array}$ & 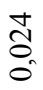 & $\underset{0}{0}$ & $\frac{\pi}{0}$ & $\frac{\infty}{n}$ & 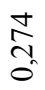 & $\frac{0}{\stackrel{1}{0}}$ & है & $\begin{array}{l}0 \\
\delta \\
0\end{array}$ \\
\hline
\end{tabular}

As a result of the optimization calculations for the CHPP operation two versions, we obtained the CHPP operation annual indices, and, based on them, the meanannual values for a fifteen-year period. Table 3 provides the main mean values for the CHPP operation over a 15 yr period.
Table 3. Main mean-annual CHPP operation indices for 15 -yr period.

\begin{tabular}{|c|c|c|}
\hline Parameters & Version 1 & Version 2 \\
\hline Power generation, kiloMW hr & 2070,9 & 2091,6 \\
\hline $\begin{array}{l}\text { Power generation by heat- } \\
\text { extraction cycle, kiloMW hr }\end{array}$ & 1848,3 & 1866,8 \\
\hline $\begin{array}{l}\text { Power generation by } \\
\text { condensation cycle, kiloMW hr }\end{array}$ & 222,6 & 224,8 \\
\hline Power supply, kiloMW hr & 1776,8 & 1794,6 \\
\hline Heat supply, kiloGkal & 4025,3 & 4065,6 \\
\hline $\begin{array}{l}\text { Standard fuel consumption, } \\
\text { kilotons of s.f. }\end{array}$ & 986,9 & 996,8 \\
\hline Turbounits' operation hours, hr. & 22775 & 23003 \\
\hline Turbounits' hours in reserve, hr. & 15714 & 15871 \\
\hline $\begin{array}{l}\text { Turbounits' hours under } \\
\text { overhaul, hr.: } \\
\text { - regular; } \\
\text { - emergency. }\end{array}$ & $\begin{array}{l}5312 \\
4662 \\
650\end{array}$ & $\begin{array}{l}5157 \\
4500 \\
657\end{array}$ \\
\hline $\begin{array}{l}\text { Boiler units' hours in operation, } \\
\text { hr. }\end{array}$ & 29751 & 30049 \\
\hline Boiler units' hours in reserve, hr. & 31167 & 31479 \\
\hline $\begin{array}{l}\text { Boiler units' hours under } \\
\text { overhaul, hr.: } \\
\text { - regular; } \\
\text { - emergency. }\end{array}$ & $\begin{array}{l}9163 \\
7609 \\
1554 \\
\end{array}$ & $\begin{array}{l}8915 \\
7345 \\
1570\end{array}$ \\
\hline Power undersupply, kiloMW hr & 0,149 & 0,151 \\
\hline Heat undersupply, kiloGcal & 37,7 & 38,1 \\
\hline Power set supply coefficient & 0,999 & 0,999 \\
\hline Heat set supply coefficient & 0,990 & 0,990 \\
\hline $\begin{array}{l}\text { CHPP possible additional profit } \\
\text { from DAM power selling, mln. } \\
\text { rbl. }\end{array}$ & 166,9 & 168,9 \\
\hline
\end{tabular}

Like one can see from Table 3, Version 2, different from Version 1 in longer overhaul periods for turbo and boiler units, has a little higher production and supply of the power and heat, than that of Version 1. Also, Version 2 features lesser total time for the equipment regular overhaul (4500 hrs), but shows a little longer period for the equipment emergency repair $(657 \mathrm{hrs})$. The set energy supply assurance coefficients for both versions are within 0,990-0,999, which evidences high reliability of supply to consumers. A possible mean extra profit from the DAM sale of power is $2 \mathrm{mln}$. rbl. (1,1\%) higher in Version 2, than that of Version 1 over the entire period. Under real conditions, the heat and power undersupply damage should be estimated for particular consumers, and it will depend both on economic factors and on the hazard of negative consequences for each consumer. To approximately estimate the damage from emergency breaks in the power supply within a public grid with different consumers, one may use averaged data on reparations to consumers with the value of about $70 \mathrm{rbl} / \mathrm{kW} \mathrm{hr}$. [18]. The values for a possible damage from the CHPP power undersupply will be $10,3 \mathrm{mln}$. rbl and 10,4 mln. rbl. for Versions 1 and 2, respectively. The difference is under $1 \%$. At the Irkutsk Oblast mean heat rate of $985 \mathrm{rbl} . / \mathrm{Gcal}$ [19], the heat undersupply for Versions 1 and 2 (in monetary terms) will be roughly $37,1 \mathrm{mln}$. rbl. and $37,5 \mathrm{mln}$. rbl., respectively. The difference is $1 \%$. Considering that the presented approximate economic estimate from the energy undersupply shows inessential difference between the versions, and that the equipment in Version 2 has a 
shorter regular overhaul downtime (and, accordingly, lower overhaul costs), one may conclude that Version 2 is more preferable for the given CHPP.

\section{Conclusion}

We developed a technique to estimate the effect of equipment reliability indices, schedules, and overhaul scopes on the CHPP operation reliability and efficiency. By the created programming and computing suite, conducted were optimization investigations into two versions (different in overhaul periods) of an industrialheating CHPP operation period.

The study was done within Research Project III.17.1.1. from the basic research programs of the Siberian Branch of the Russian Academy of Sciences, Reg. No. AAAA-A17117030310433-6

\section{References}

1. Pshenichnikov S, and I. Sumskoy. Combustion Plant Energy Equipment Wear. "Russia's United Power Systems" RC ASO rating [e-resource] - 2005. - 12. Access mode: $\quad \underline{\text { http://www.e-m.ru/er/2005- }}$ 12/22870/?phrase id=333686>, in Russian.

2. Barinov V.A, V.A. Saveliev, M.G. Sukharev, et al. Reliability of Liberalized Energy Systems // Novosibirsk: Nauka (Science), 2004. - P. 333, in Russian.

3. Semenov V.G. District Heating Cogeneration under present-day market conditions // Energetics Reliability and Safety. 2012. No. 18. Pp. 67-73, in Russian.

4. Sukhareva E.V., and E.M. Lisin. Analyzing problems of decrease in the efficiency of CHPP industrial-economic activities under power market conditions //In: Social Responsibility of Business. International Theoretical and Practical Conference: proceedings. Ed.: Yu.A.Anisimova. 2014. Pp. 268-277, in Russian.

5. Rezinskikh V.F., and A.G. Tumanovskiy. Improving Reliability and Efficiency of CP operating equipment // New in Russian Electric Power Industry. 2011. No. 4. Pp. 5-13, in Russian.

6. Popyrin L.S. Mathematical modeling and optimizing heat-and-power facilities. - Moscow: Energiya (Energy), 1978. - P. 416, in Russian.

7. Kler A.M., N.P. Dekanova, E.A. Tyurina, et al. Thermal Power Systems: Optimizing Research. Novosibirsk: Nauka (Science), 2005. - P. 236, in Russian.

8. Shchinnikov P.A, G.V. Nozdrenko, O.V. Borush, et al. Optimizing the CHPP generating unit operation modes // Izvestiya RAN. Energetika. (Proceedings of the Russian Academy of Sciences. Power Engineering). 2014. - No. 3. - Pp. 54-60.

9. Stojiljkovic, M., et al:: Mathematical modeling and optimization of tri-Generation systems with reciprocating engines. THERMAL SCIENCE: Year 2010, Vol. 14. - No. 2. - P. 541-553.
10. SO 34.04.181-2003 "Rules to organize maintenance service and repair of the equipment, buildings, and structures at power plants and grids" Russia's Unified Energy System, in Russian.

11. Sokolov E.Ya. District Heating Cogeneration and Heating Systems. - Moscow: Energoatomizdat (Energy and Nuclear Power Publishers), 1982. - P. 360, in Russian.

12. Kler A.M., A.S. Maksimov, A.V. Chalbyshev, and E.L. Stepanova. Optimizing the CHPP operation modes to maximize profit under the conditions of the electric power balancing market // Izvestiya RAN. Energetika. (Proceedings of the Russian Academy of Sciences. Power Engineering). 2014. No. 2. With. Pp. 71-80, in Russian.

13. Kler A.M., A.S. Maksimov, E.L. Stepanova, and A.V. Chalbyshev. Problems of internal optimization of the CHPP operation regimes at the Day-Ahead Market // Energetik (Power Engineer). 2015. No. 8. Pp. 20-23, in Russian.

14. Kler A.M., N.P. Dekanova, S.K. Skripkin, et al. Mathematical modeling and optimizing in the problems of operational control at combined heat-and-power plants. - Novosibirsk: Nauka (Science). Sib. Enterprise of RAS, 1997. - P. 120, in Russian.

15. Kler A.M., N.P. Dekanova, and E.L. Stepanova. Optimizing the CHPP main equipment configuration of major power sources // Izvestiya RAN. Energetika. (Proceedings of the Russian Academy of Sciences. Power Engineering), 2004. - No. 6. - Pp. 43 - 52, in Russian.

16. Kler A.M., and E.L. Stepanova. Optimizing the CHPP main equipment configuration in normal and emergency operation modes // Metodicheskiye voprosy issledovaniya nadyozhnosti bol'shikh system energetiki (Methodical issues of studying reliability of the power engineering major systems). Issue 64 Reliability of power engineering systems: achievements, problems, prospects // Ed.-in-chf. N.I. Voropay - Melentiev Energy Systems Institute of the Siberian Branch of the Russian Academy of Sciences, 2014. - Pp. 346 - 357, in Russian. 17. Kler A.M., E.L. Stepanova, and A.S. Maximov. Solving the sequence of problems to minimize undersupplies of heat and power for post-emergency conditions of the CHPP operation // Metodicheskiye voprosy issledovaniya nadyozhnosti bol'shikh sistem energetiki (Methodical issues of studying reliability of the power engineering major systems). Issue 65 Reliability of liberalized power systems / Ed.-in-chf. N.I. Voropay - Melentiev Energy Systems Institute of the Siberian Branch of the Russian Academy of Sciences, 2015. - Pp. 415 - 424, in Russian.

18. Reference book on designing power grids / Ed. by D.L.Faybisovich. - 4th Issue, revised and supplemented. - Modcow: ENAS Publishers, 2012. - Pp. 376, in Russian.

19. Irkutskenergosbyt LLC Official Website [eresource] $<$ https://sbyt.irkutskenergo.ru $>$.

Online references will be linked to their original source, only if possible. To enable this linking extra care should be taken when preparing reference lists. 